\title{
The role of acceptance and values in quality of life in patients with an acquired brain injury: a questionnaire study
}

\author{
Gunther Van Bost $^{\text {Corresp.., }}{ }^{1,2}$, Stefaan Van Damme ${ }^{1}$, Geert Crombez $^{1}$ \\ 1 Department of Experimental-Clinical and Health Psychology, Ghent University, Ghent, Belgium \\ 2 Unit Acquired Brain Injury, Centrum voor Ambulante Revalidatie Ter Kouter, Deinze, Belgium \\ Corresponding Author: Gunther Van Bost \\ Email address: gunther.vanbost@ugent.be
}

Objective: An acquired brain injury ( $A B \mathrm{~B})$ is a challenge for an individual's quality of life (QOL). In several chronic illnesses acceptance has been found to be associated with a better Health related Quality of Life. This study investigated whether this relationship is also found in patients with $\mathrm{ABI}$. We also explored the impact of the perceived ability to live according to one's own values (life-values-match). Methods: 68 individuals (18-65 years of age) with an acquired brain injury completed a battery of questionnaires. The relations between Health related QOL (SF-36) and disease specific QOL (EBIQ; European Brain Injury Questionnaire), and personal values (Schwartz Values Inventory) and acceptance (ICQ; Illness Cognitions Questionnaire) were investigated. An additional question measured the life-values-match. Rehabilitation professionals reported the extent of impairment involved. Results: Acceptance was positively associated with mental aspects of Health related QOL and the EBIQ Core Scale, after demographic variables and the extent of impairment were introduced in the regression. In a post hoc analysis we found that the life-values-match mediated the relationship between acceptance and mental aspects of QOL. Conclusion: In patients with an $A B I$, promoting acceptance may be useful to protect QOL. Strengthening the life-values-match may be a way to accomplish this. 


\section{The role of acceptance and values in quality of life in}

\section{patients with an acquired brain injury: a questionnaire}

\section{study}

Gunther Van Bost ${ }^{12}$, Stefaan Van Damme ${ }^{1}$, Geert Crombez ${ }^{1}$

${ }^{1}$ Department of Experimental Clinical and Health Psychology, Ghent University, Ghent, Flanders, Belgium

${ }^{2}$ Unit Acquired Brain Injury, CAR Ter Kouter, Deinze, Flanders, Belgium

Corresponding Author:

Gunther Van Bost ${ }^{1}$

Dunantlaan 2, Gent, Flanders, B-9000, Belgium

Email address: Gunther.VanBost@UGent.be 


\begin{abstract}
Objective: An acquired brain injury (ABI) is a challenge for an individual's quality of life (QOL). In several chronic illnesses acceptance has been found to be associated with a better Health related Quality of Life. This study investigated whether this relationship is also found in patients with ABI. We also explored the impact of the perceived ability to live according to one's own values (life-values-match).

Methods: 68 individuals (18-65 years of age) with an acquired brain injury completed a battery of questionnaires. The relations between Health related QOL (SF-36) and disease specific QOL (EBIQ; European Brain Injury Questionnaire), and personal values (Schwartz Values Inventory) and acceptance (ICQ; Illness Cognitions Questionnaire) were investigated. An additional question measured the life-values-match. Rehabilitation professionals reported the extent of impairment involved.
\end{abstract}

Results: Acceptance was positively associated with mental aspects of Health related QOL and the EBIQ Core Scale, after demographic variables and the extent of impairment were introduced in the regression. In a post hoc analysis we found that the life-values-match mediated the relationship between acceptance and mental aspects of QOL.

Conclusion: In patients with an ABI, promoting acceptance may be useful to protect QOL. Strengthening the life-values-match may be a way to accomplish this. 
1

2

3

4

5

6

7

8

9

10

11

12

\section{Introduction}

An acquired brain injury (ABI) may well be one of the greatest challenges to live with [32]. A systematic review [26] reported a high prevalence of health problems during the first year after the injury, and even in the long-term patients show large deficits in mobility, communication and cognitive functions. People may suffer from motor disorders such as hemiplegia, but also experience aphasia or attention and memory problems.

Interestingly, health related quality of life (HRQOL), here defined as the perception of how illness and treatment affect physical, mental and social aspects of life [10] is only weakly related to the severity of impairment in ABI [13]. This observation may indicate that other variables affect HRQOL. One such variable that may account for HRQOL despite adversities is the way patients cope with their problem.

Coping is an elusive construct, and there are myriad ways of measuring and classifying coping strategies. After an extensive review of the literature, Skinner et al. (2003) [33] concluded that the dual-model of coping [4] was exemplary for its scope and clarity. The dual-process model was originally developed to describe the self-regulatory processes in an ageing population, but has been widely adopted to cope with various adversities such as chronic pain [19] or chronic fatigue syndrome [42]. According to this model, the first mode of coping with adversity is to identify the factors that hinder goal pursuit and to attempt to reduce or eliminate the obstacle. This is called 'assimilative' coping. When an obstacle is soluble, this type of problem solving is considered adaptive. However, when obstacles are uncontrollable, a slavish adherence to assimilative coping may prove futile and only increase frustration and distress.

'Accommodative' coping may then be preferred. During this type of coping patients accept that 
24 the problem cannot be resolved, disengage from the pursuit of the blocked goal, and finally

25 engage in new or reset goals according to one's values [48].

26 Without doubt, assimilative coping can be a useful strategy in ABI. Rehabilitation has

27 proven effective, and studies indicate that more intensive rehabilitation is associated with more

28 rapid gain [39]. Nevertheless, a complete return to the pre-injury status is often unlikely.

29 Individuals with severe memory problems will not be able to follow higher education; and a

30 teacher with global aphasia will experience difficulties to teach. Although problem solving

31 strategies are considered adaptive [1;48], an accepting attitude towards problems that cannot be

32 resolved may prove also beneficial. It should be clear that acceptance is not resigning or giving

33 up [28]. It is the acknowledgement that a problem is not likely to disappear, and it is better to

34 shift the attention and efforts towards other aspects of life according one's personal values.

35 According to Klonoff (2010) [18], acceptance after brain injury means "patients' ability and

36 willingness to cope with their new reality and identity" (p. 100).

37 The role of acceptance has been documented in various chronic illnesses amongst which

38 chronic pain [43], chronic fatigue syndrome [42], multiple sclerosis [24], and chronic kidney

39 disease [27]. Evidence has accumulated that attempts to control uncontrollable events may bring

40 along cognitive and emotional costs, whereas accepting the uncontrollable nature of illnesses

41 allows for a re-engagement in feasible activities [49]. Research on acceptance in patients with

42 ABI is limited, but promising. One study [34] has revealed a positive relationship between

43 acceptance, measured with the Acceptance of Disability Scale [22], and HRQOL in individuals

44 with an ABI ten years post-injury. Also, acceptance has been associated with less depression,

45 after controlling for demographic factors in patients with stroke [38]. These results require

46 replication and corroboration. 
Another question pertains to how exactly acceptance may lead to a better HRQOL.

48 Human behavior is often guided by values, which have been found to be largely consistent across

49 cultures [31]. On the one hand, certain values may directly lead to behavior or cognitions that

50 enhance one's HRQOL. For example, students having certain values (i.e. achievement,

51 stimulation and self-direction) may report a more positive sense of wellbeing than when they

52 have other values (e.g. conformity and security) [29]. On the other hand, being successful at

53 living according to personal values, regardless of what those values are, may be essential for

54 HRQOL. For example, chronic pain patients who report to live according to their values reported

55 less disability, depression, and pain-related anxiety [23]. It may be that individuals experience

56 the impairments by the brain injury as less distressing as long as these do not interfere with their

57 life values.

\section{Study objective}

This study was designed to investigate the role of acceptance in the HRQOL in patients with ABI. First, we aimed at replicating and extending the finding that self-reported acceptance is associated with higher scores on measures of HRQOL, using the Short Form Health Survey (SF-36) [45] and the European Brain Injury Questionnaire (EBIQ) [40,36]. We expect to see

64 similar results as previous studies with chronic medical conditions: acceptance of illness is related to a higher HRQOL. Nevertheless, we expect a stronger effect on the mental component than on the physical component of HRQOL, as we consider it unlikely that acceptance will alter

67 for example the self-reported ability to walk again or climb the stairs. Second, we investigate the 68 specific role of values. Given the fact that in a healthy population certain values (i.e.

69 achievement, stimulation and self-direction) were associated with more positive outcomes, we 
70 expected a similar pattern in ABI. Also, individuals who consider themselves as part of a larger

71 reality (e.g. nature, humanity) will have a high score on the value Universalism, and may find it

72 easier to focus on a positive project, even with their disability. Third, we also explored whether

73 living according one's own values (i.e. life-values-match), independent from the specific value,

74 was associated with more positive outcomes.

75

76

77

78

79

80

81

82

83

84

85

86

87

88

89

90 91 necessary.

92

\section{Participants}

\section{Materials and method}

Sixty-eight persons with an acquired brain injury participated in this study. A large majority $(\mathrm{N}=58)$ was recruited from three outpatient rehabilitation units in Flanders (Dutch-speaking region in the north of Belgium); four patients from a specialized psychiatric unit; and four from a private practice of a specialised psychotherapist. These outpatient rehabilitation units work with ABI-patients, regardless of the aetiology of the brain injury, to maximize their level of activities and participation as defined by the International Classification of Functioning, Disability and Health of the World Health Organisation [3]. The study protocol was approved by the Ethical Committee of the Faculty of Psychology and Educational Sciences of Ghent University (2006/39). All patients provided written informed consent. When there was doubt about the ability of a patient to make autonomous decisions about the participation, a relative was asked to provide additional consent. This happened twice. A graduate student was present during the study to help the respondents to stay focused, to provide explanation when the respondents did not understand the question and to provide practical help to fill out the questionnaires when 
93

94

95

96

97

100

101

102

103

104

105

106

107

108

109

110

111 Helplessness (6 items, e.g. “My illness frequently makes me feel helpless”), (2) Acceptance (6

112 items, e.g. "I have learned to live with my illness") and (3) Disease benefits (6 items, e.g. "My

113 illness has made me appreciate life more"). Items are rated using a 4-point scale (1= "not", 2= "a

114 little", 3= "strongly", 4= "completely"). The ICQ hasn't been used before in a brain-injured 
115 population, but the three-factor structure and psychometric properties have been found to be

116 good in a Dutch-speaking population of persons with chronic pain and chronic fatigue [19].

117 The Schwartz Values Questionnaire - Dutch version (SVQ) [31] measured specific

118 personal values. It consists of 58 items and 10 values: (1) Power (5 items, e.g. "social power"),

119 (2) Achievement (5 items, e.g. "successful”), (3) Hedonism (3 items, e.g. "enjoying life”), (4)

120 Stimulation (3 items, e.g. "an exciting life"), (5) Self direction (5 items, e.g. "choosing own

121 goals"), (6) Universalism (8 items, e.g. “equality”), (7) Benevolence (5 items, e.g. "helpful”), (8)

122 Tradition (5 items, e.g. "respect for tradition"), (9) Conformity (4 items, e.g. "politeness"), and

123 (10) Security (5 items, e.g. "family security"). Each item is followed by a short explanatory

124 phrase (e.g. FAMILY SECURITY (security for those you love)). Patients are asked to rate the

125 importance of each value item as guiding principle in their life on a 9-point scale, ranging from -

1261 (“opposed to my principles"), through 0 ("not important"), to 7 (“of supreme importance"). In

127 a large international study [31] the 10-factor structure has been confirmed and the psychometric

128 properties were satisfactory. As far as we know, this questionnaire hasn't been used before with

129 brain injured patients.

130 At the end of the SVQ, respondents were asked to what extent they felt able to live

131 according to their own personal values. This "life-values-match" was specifically developed for

132 this study. Participants responded on a single 7-point scale $(1=$ no match at all; 7= perfect match

133 between the actual life and valued life) to what extent they were overall able to live according to

134 values, mentioned in the SVQ". This "life-values-match" should be seen as an extension of the

135 SVQ rather than as an independent instrument. Respondents have just answered 58 questions

136 concerning values and were then asked about their ability to live according to those values.

137 Without these previous questions, this item may lose its meaning or understandability. 
36) [45] and by the Dutch version [40] of the European Brain Injury Questionnaire (EBIQ) [36].

140 The SF-36 consists of 36 items, and is recommend by Polinder, et al. (2015) [26] as a generic

141 measure of QOL in patients with TBI. This study reports an internal consistency ranging from

142 fair to good and a good content validity across various studies. The SF-36 yields an 8-scales

143 health profile, and two components scores: a physical health component (e.g. Accomplished less

144 as a result of your physical health) and a mental health component (e.g. Did work or activities

145 less carefully than usual as a result of emotional problems.). Büllinger, et al. (2002) [5]

146 recommended the EBIQ as a disease-specific instrument for QOL-research with a brain-injured

147 population. Teasdale et al. (1997) [36] derived 8 scales: (1) Somatic (8 items, e.g. "Lack of

148 energy"), (2) Cognitive (13 items, e.g. "Trouble concentrating”), (3) Motivation (5 items, e.g.

149 "Lack of interest in hobbies in the home"), (4) Impulsivity (13 items, e.g. "Behaving tactlessly"),

150 (5) Depression (9 items, e.g. "Feeling hopeless about the future"), (6) Isolation (4 items, e.g.

151 “Thinking only of oneself”), (7) Physical (6 items, e.g. "Needing help with personal hygiene”,

152 (8) Communication (4 items, e.g. "Difficulty in communication") and (9) Core (34 items, e.g.

153 "Problems in general"). To obtain a single indicator of disease specific QOL, we used the Core

154 Symptoms scale, which consisted of the most sensitive items from the 8 subscales (e.g. Lack of

155 energy or being slowed down) to be rated on a 3-point scale ("not at all", "a little", "a lot"). The

156 first and the last author, and two other Dutch speaking persons, translated the EBIQ in Dutch in

157 2005. The first author made a back-translation and asked Prof. Teasdale to check the back-

158 translation. He had some minor remarks that have been addressed in the final version. Reliability

159 and validity of the English version of the SF-36 [12] and the EBIQ [35] have proven satisfactory 
160 in a sample of brain-injured patients. This is the first time that the Dutch version of the

161 questionnaire is used.

162 The therapist who was responsible for the rehabilitation program, provided four expert

163 ratings, respectively for the level of motor impairment, communication impairment, cognitive

164 impairment and self-awareness impairment. For each impairment, a 7-point scale $(7=$ perfect

165 age-appropriate functioning, 1 = extremely impaired) was used.

\section{Results}

Data were checked for normality and we didn't find violations of the assumptions for

169 further analyses. The sample was a convenience sample, and no power calculation was used.

170 Mean scores, standard deviations, internal consistency (Cronbach's $\alpha$ ) for acceptance, the life-

171 values-match and the different indicators of HRQOL are presented in Table 1. A significant

172 difference between the results of participants with a TBI and those after a stroke was observed

173 for the Physical Component of the SF-36 $(\mathrm{t}(61)=-2.06) ; \mathrm{p}<.05)$. There were no significant

174 differences found for the Mental Component $(\mathrm{t}(61)=-1.17$; ns) or the EBIQ Core $(\mathrm{t}(61)=-.58$;

175 ns). As statistical power was low we did not include aetiology in further analyses.

176 Pearson correlations can be seen in Table 1. None of the demographic factors had a

177 significant correlation with Mental Component of the SF-36 or disease specific HRQOL. Male

178 gender reported more acceptance (ICQ Acceptance, $\mathrm{t}(66)=2.11 ; \mathrm{p}<.05$ ) and a higher physically

179 quality of life (Physical Component of the SF-36, $t(66)=2.26 ; \mathrm{p}<.05$ ). The difference between

180 men and women for the ICQ Acceptance scale is 2.38 points (). For the Physical Component the

181 difference was $5.39(\mathrm{t}(66)=2.26 ; \mathrm{p}<.05)$. Age was only negatively correlated with the Physical

182 Component of the SF-36. Education was related with the Physical Component $(\mathrm{F}(10,56)=2.06$; 
$183 \mathrm{p}<.05)$, but not with the other indicators of QOL of Acceptance. Self-awareness, as rated by the

184 therapist, was negatively correlated with the Physical Component of the SF-36 and positively

185 with Acceptance. Motor problems correlated negatively with the Physical Component of the SF-

186 36. Communication problems were negatively correlated with the Physical Component of the

187 SF-36 and also negatively correlated with Acceptance. Cognitive problems had a negative

188 correlation with the life-values-match. Acceptance was positively related to the Physical and the

189 Mental Component of the SF-36 and was negatively related to the EBIQ Core Scale. The only

190 scale of the Schwartz Values Inventory that was related to acceptance was Universalism. None

191 of the scales of the Schwartz Value Inventory were related to HRQOL measures. However, the

192 single item life-values-match was strongly related to the SF-36, disease-specific HRQOL and

193 acceptance.

Insert Table 1 here

The role of Acceptance in HRQOL was investigated by a series of multiple regression analyses, with the Physical and Mental component of the SF-36 and the EBIQ Core Scale as dependent variables. In each analysis age, gender and education were entered in a first step. In a second step, the time since injury was entered. The four expert ratings of the illness characteristics were entered in the third step. In the fourth and final step, acceptance was entered.

202 The results of the final model of these analyses are shown in Table 2. In the analysis with the 203 Physical Component (SF-36) as the dependent variable the outcome was significantly higher for 204 male gender $(\beta=0.21, \mathrm{p}<0.05)$, and with less severe Motor impairments $(\beta=-0.54, \mathrm{p}<0.001)$, 205 and a lower Self-Awareness $(\beta=-0.25, \mathrm{p}<0.05)$. The impact of Acceptance approached 
206 significance $\left(\left(\mathrm{F}_{\text {change }}(1,57)=3.73, \mathrm{p}<.058\right) . \mathrm{R}^{2}\right.$ change after introduction of Acceptance was 0.03 .

207 The final model explained $45 \%$ of the variance in the SF-36 Physical Component scores.

208 In the analysis with the Mental Component (SF-36) as dependent variable none of the

209 demographic factors or illness characteristics produced a significant effect. The Mental

210 Component (SF-36) was only positively accounted for by Acceptance $\left(\mathrm{F}_{\text {change }}(1,57)=16.95\right.$,

$211 \mathrm{p}<.001) . \mathrm{R}^{2}$ change after introduction of Acceptance was 0.22 . The final model explained $16 \%$

212 of the variance in the SF-36 Mental Component scores.

213 Also in the analysis with the EBIQ Core Scale as dependent variable there was no effect

214 of demographic variables, but there was a positive effect of Self-awareness $(\beta=0.33, p<0.05)$.

215 Acceptance had an unique explanatory value $\left(\mathrm{F}_{\text {change }}(1,57)=21.01, \mathrm{p}<.001\right)$ beyond the other

216 variables. A higher acceptance was linked with less disease specific complaints. $\mathrm{R}^{2}$ change after

217 introduction of Acceptance was 0.25 . The final model explained $23 \%$ of the variance in the

218 EBIQ Core Scale scores.

219

220

Insert Table 2 here

221

222

In further post-hoc exploratory analyses, we investigated whether the life-values-match

223

was a mediator of the relationship between acceptance and HRQOL. A mediator is "a variable,

224

that serves to explain the process by which a predictor significantly affects an outcome, such that

225

the predictor is associated with the mediator, which in turn is associated with the outcome" [15].

226

To test for mediation, the following conditions should be met: (a) a significant association

227 between the predictor and the outcome, (b) a significant association between the predictor and

228 the mediator, and (c) a significant association between the mediator and the outcome, after 
229 controlling for the effect of the predictor. If these conditions are met, then one examines whether

230 the predictor-outcome-effect is less after controlling for the mediator. The Sobel-test, which is

231 basically a specialized t-test, is used to determine if this reduction in effect is significant. These

232 conditions were only met for the effect of acceptance on the mental component of the SF-36 and

233 on the Core Scale of the EBIQ. Hence, a mediation analysis was only performed for these

234 associations. As shown in Figure 1 we found that the life-values-match significantly mediated

235 the relationship between Acceptance and the Mental Component of HRQOL (SF-36). The

236 remaining predictive value of Acceptance in explaining the Mental Component of HRQOL was

237 significantly reduced by the inclusion of the life-values-match (Sobel Test Statistic $=3.11, \mathrm{p}<$

238 .01). Also the mediation effect of the life-values-match on the relationship between Acceptance

239 and the Core Scale of the EBIQ was significant (Sobel Test Statistic $=-2.83, \mathrm{p}<.01$ ).

Insert Figure 1 here

\section{Discussion}

This study revealed that acceptance was uniquely associated with measurements of general and disease specific quality of life in ABI patients. This is in line with the work of Snead \& Davis (2002) [34], who concluded that greater acceptance of disability was associated with higher quality of life in a sample of 40 individuals with an acquired brain injury. At first sight this may be at odds with the results of Wolters-Grégorio et al. (2010) [48], who found that an active problem-focused coping style is associated with a higher quality of life in a sample of 110 individuals in the chronic phase after brain injury, whereas more passive emotion-focused coping

251 styles turned out to be more maladaptive. However, acceptance is not to be understood as a 
252 passive, emotion-focused process, but a way of coping in which individuals disengage from

253 unattainable goals and pursue more feasible goals.

254 Striving for personal goals assigns meaning, structure and direction to an individual's life 255 and is known to be associated with wellbeing [6]. According to Brandstädter and Rothermund

256 (2002) [4] when people get older, they invest less in trying to solve the problems that block their

257 goals, and invest more in the adaption of their goals so that these become achievable. In a similar 258 way, a brain injury blocks individuals' personal goals, causing distress. One way of coping with 259 such distress is to attempt restoring the status and functioning as before the injury. Patients may 260 then engage in intensive rehabilitation efforts, retraining the damaged functions to be able to 261 overcome activity and participation restrictions [3]. At a certain point this strategy is no longer

262 useful, because certain impairments are impossible to overcome. Keep fighting these

263 impairments may then lead to more frustration and a lower HRQOL. If acceptance is considered

264 part of accommodative coping, one may understand how this type of coping contributes to a

265 better mental wellbeing. Conrad, et al. (2010) [6] have found similar results about the impact of

266 the attainability of life goals on subjective wellbeing in a brain-injured population.

267 A particular challenge in patients with $\mathrm{ABI}$ is that some brain injury related problems, 268 such as cognitive inflexibility and low self-awareness may complicate a shift to accommodative 269 coping. Especially the lack of cognitive flexibility may lead to perseveration and difficulties 270 disengaging from unattainable goals. However, Wolter-Grégorio, et al. (2015) [47] found no 271 relationship between measures of coping and life satisfaction and neuropsychological test results

272 of executive functioning, although there was a relationship with self-reported problems in

273 executive functioning. Further research is needed to clarify this relationship. 
This study demonstrated the importance of values. Of particular interest is the finding that

275 the relationship between acceptance and mental HRQOL was mediated by the perceived ability

276 to live according to one's values. Possibly, important changes in life because of a brain injury are

277 easier to accept as long as the new life is still in concordance with one's values. For example, a

278 former engineer who strongly values professional success and being respected by others may

279 experience a good quality of life by growing and selling vegetables on a small scale, as long as

280 he feels successful and respected doing so.

281 We found no evidence that certain specific values were superior to others in explaining

282 quality of life, although there was a correlation between Acceptance and Universalism. This is in

283 line with the findings of Sagiv \& Schwartz (2000) [29] in a student population, who also did not

284 find that particular values had an effect upon wellbeing. Of further note is that the size of the

285 association between acceptance and the physical HRQOL is much smalle than the one between

286 acceptance and the mental component. This finding was not unexpected. The self-perceived

287 physical capabilities of brain-injured individuals are probably largely determined by

288 demographic factors and the impairments of the brain injury [2], probably leaving not much

289 room for effects of coping.

290 A better understanding of the determinants of the acceptance process can contribute to

291 the development of intervention techniques, aimed at a better quality of life of ABI patients.

292 More research is needed to study these processes. Acceptance and Commitment Therapy (ACT)

293 [14] has made acceptance an important focus of therapeutic interventions. In chronic pain

294 patients, there is evidence that therapeutic interventions aimed at acceptance and values-based-

295 action [44] are effective. We may expect similar results with a brain-injured population, given

296 that in post hoc analyses we found that the relationship between acceptance and mental QOL and 
297 between acceptance and the disease-specific QOL was mediated by the perceived ability to live 298 according to one's values. This is also found in the few available studies that have investigated 299 the possibilities of ACT with an ABI-population [17; 46].

300 This study has some limitations. First, a cross-sectional design was used, which makes

301 causal inferences impossible. The reversed direction is also possible: people experiencing an

302 overall higher HRQOL may be more able at withstanding adversity and may find it easier than

303 others to accept this reality. Second, impairment was only assessed by the therapist and only in

304 four areas. Although patients with a severely impaired self-awareness were excluded from our

305 study, several respondents were less able to report the consequences of their brain injury,

306 minimized them or could not understand their impact. A correct appreciation of the situation

307 might be necessary for the acceptance process, resulting in a positive relationship between self-

308 awareness, life-values match and acceptance. Third, we only investigated HRQOL, ignoring life

309 satisfaction or other aspects of QOL after brain injury [10]. The impact of psychological factors

310 as acceptance on life satisfaction may be stronger, knowing that the role of demographic factors

311 and impairments is very limited there [25]. Fourth, we need to be cautious with the interpretation

312 of the results with the Schwartz Values Inventory (SVI). We observed that for many patients the

313 abstract phrasing in the questionnaire was difficult, even with help. We experienced that many

314 patients with $\mathrm{ABI}$ had to be reminded of the distinction between the values as a guiding principle

315 in their life (e.g. being active) and the actual status of being active. We tried to compensate for

316 this with the help of a graduate student as a research assistant. The graduate student was not

317 blind to the research objectives and we may not exclude the possibility that this affected the

318 results. Fifth, the sample size was moderate, making it difficult to perform subgroup analysis.

319 We chose to include demographic factors and illness characteristics in the analysis anyway, as it 
320 is still a common idea that these factors are important for the mental aspects of subjective quality

321 of life. By showing that such a relation is hard to find, we hope that one will put more emphasis

322 on other factors, such as acceptance.

323 Despite these limitations this study has revealed similar effects of acceptance as were

324 previously observed in other chronic conditions. It also suggests the importance of reducing the

325 discrepancy between the valued way of living and the actual way of living in protecting patients'

326 HRQOL. These findings are useful for the development of clinical interventions, specifically

327 aimed at an ABI-population. When complete recovery is no longer feasible, it may be useful to

328 assess the basic values of patients. This can help therapists to guide people in their search for

329 other meaningful activities in life.

331 References

332 1. Anson K., Ponsford, J. 2006. Coping and emotional adjustment following traumatic brain 333 injury. Journal of Head Trauma Rehabilitation 21:248-259

334 2. Berzina G, Paanalahti M, Lundgren-Nillson A, Sunnerhagen KS. 2013. Exploration of 335 some personal factors with the International Classification of Functioning, Disability and 336 Health Core Set for stroke. Journal of Rehabilitation Medicine 45:609-615

3. Bilbao A, Kennedy C, Chatterji S, ÜstÜn B, Vásquez Barquero J, Barth T. 2003. The ICF: Applications of the WHO model of functioning, disability and health to brain injury rehabilitation. Neurorehabilitation 18:239-250

4. Brandtstädter J, Rothermund K. 2002. The life-course dynamics of goal-pursuit and goal adjustment: A two-process framework. Development Review 22:117-150 
342 5. Bullinger M \& The TBI Consensus Group. 2002. Quality of life in patients with traumatic

343 brain injury-basic issues, assessment and recommendations. Restorative Neurology and

$344 \quad$ Neuroscience 20:111-124

345 6. Conrad N, Doering B, Rief W, Exner C. 2010. Looking beyond the importance of life goals.

346 The personal goal model in neuropsychological rehabilitation. Clinical Rehabilitation 24:

$347 \quad 431-443$

348 7. Corrigan JD, Bogner J. 2004. Latent Factors in Measures of Rehabilitation Outcomes After

349 Traumatic Brain Injury. Journal of Head Trauma Rehabilitation 16:445-458

350 8. Creswell LD, Welch WT, Taylor SE, Sherman DK, Gruenewald TL, Mann T. 2005.

351 Affirmation of Personal Values Buffers Endocrine and Psychological Stress Responses.

$352 \quad$ Psychological Science 16:846-851

353 9. Diener E, Emmons RA, Larsen RJ, Griffin S. 1985. The Satisfaction With Life Scale.

$354 \quad$ Journal of Personality Assessment 49:71-75

355 10. Dijkers MP. 2004. Quality of Life After Traumatic Brain Injury: A Review of Research 356 Approaches and Findings. Archives of Physical Medicine and Rehabilitation 48:S21-S35

357 11. Evers AM, Kraaimaat FW, Van Lankveld W, Jongen PJH, Jacobs WG, Bijlsma JWJ. 2001.

358 Beyond unfavourable thinking: The Illness Cognition Questionnaire for chronic diseases.

$359 \quad$ Journal of Consulting and Clinical Psychology 69:1026-1036

360 12. Findler M, Cantor J, Haddad L, Gordon W, Ashman T. 2001. The reliability and validity 361 of the SF-36 health survey questionnaire for use with individuals with traumatic brain 362 injury. Brain Injury 15:715-723 
363 13. Grauwenmeijer E, Heijenbrok-Kal MH, Ribbers GM. 2014. Health-related Quality of Life

364 Years after Moderate to Severe Traumatic Brain Injury: A Prospective Cohort Study.

365 Archives of Physical Medicine and Rehabilitation 95:1268-1276

366 14. Hayes S, Luoma J, Bond F, Masuda A, Lillis J. 2006. Acceptance and Commitment

367 Therapy: Model, processes and outcomes. Behaviour Research and Therapy 44:1-25

368 15. Holmbeck GN. 2002. Post-hoc probing of significant moderational and meditational

369 effects in studies of pediatric populations. Journal of Pediatric Psychology 27:87-96

370 16. Jacobsson LJ, Westerberg G, Lexell J. 2010. Health-related quality-of-life and life

371 satisfaction 6-15 years after traumatic brain injuries in northern Sweden. Brain Injury

$372 \quad 24: 1075-1086$

373 17. Kangas M, McDonald S. 2011. Is it time to act? The potential of acceptance and 374 commitment therapy for psychological problems following acquired brain injury, $375 \quad$ Neuropsychological Rehabilitation 21:250-276

376 18. Klonoff P. 2010. Increasing acceptance. In Klonoff P. Ed. Psychotherapy after brain 377 injury: principles and techniques. New York: The Guilford Press.

378 19. Lauwerier E, Crombez G, Van Damme S, Goubert L, Vogelaers D, \& Evers A. 2010. The 379 construct validity of the Illness Cognition Questionnaire: The robustness of the three-factor 380 structure in patients with chronic pain and chronic fatigue. International Journal of 381 Behavioral Medicine, 17:90-96.

382 20. Lauwerier E, Van Damme S, Goubert L, Paemeleire K, Devulder J, Crombez G. 2012. To 383 control or not? A motivational perspective on coping with pain. Acta Neurologica Belgica 384 112:3 -7 
385 21. Lazarus RS, Folkman S. 1984. Stress, appraisal, and coping. New York: Springer $386 \quad$ Publishing.

387 22. Linkowski DC. 1971. The acceptance of disability scale. Washington, DC: George 388 Washington University Press.

389 23. McCracken LM., Yang SY. 2006. The role of values in a contextual cognitive-behavioral $390 \quad$ approach to chronic pain. Pain 123:137-145

391 24. Pakenham K. 2006. Investigation of the coping antecedents to positive outcomes and 392

25. Pierce CA, Hanks RA. 2006. Life satisfaction after traumatic brain injury and the World Health Organisation model of disability. American Journal of Physical Medicine and Rehabilitation 85:889-898

26. Polinder S, Haagsma JA, van Klaveren D, Steyerberg EW, Van Beeck EF. 2015. Healthrelated quality of life after TBI: a systematic review of study design, instruments, measurement properties, and outcome. Population Health Metrics 13:1-12

27. Poppe C, Crombez G, Hanoulle I, Vogelaers D, Petrovic M. 2013. Improving Quality of Life in Patients with Chronic Kidney disease: Influence of Acceptance and Personality. Nephrology Dialysis Transplantation 28:116-121 with pain? A Q-methodological analysis of the diverse understandings of acceptance of chronic pain. Social Science and Medicine 56:375-386

29. Sagiv L, Schwartz, SH. 2000. Value priorities and subjective well-being: direct relations and congruity effects. European Journal of Social Psychology 30:177-198 
407

408

409

410

411

412

413

414

415

416

417

418

419

420

421

422

423

424

425

426

427

428

30. Scholten AC, Haagsma JA, Adriessen TMJC, Vos PE, Steyerberg EW, van Beek EF, Polinder S. 2015. Health-related quality of life after mild, moderate and severe traumatic brain injury: Patterns and predictors of suboptimal functioning during the first year after injury. Injury-International Journal Of The Care Of The Injured 46:616-624

31. Schwartz SH, Boehnke, K. 2004. Evaluating the structure of human values with confirmatory factor analysis. Journal of Research in Personality 38:230-255

32. Seibert S, Reedy P, Hash J, Webb A, Stridh-igo P, Basom J, Zimmerman C. 2002. Brain injury: quality of life's greatest challenge. Brain injury 16:837-848

33. Skinner EA, Edge K, Altman J, Sherwood H. 2003. Searching for the structure of coping: a review and critique of category systems of classifying ways of coping. Psychological Bulletin 195:216-269

34. Snead SL, Davis J. 2002. Attitudes of individuals with acquired brain injury towards disability. Brain Injury 16:947-953

35. Sopena S, Dewar BK, Nannery R, Teasdale TW, Wilson BA. 2007. The European Brain Injury Questionnaire (EBIQ) as a reliable outcome measure for use with people with brain injury. Brain Injury 21:1063-1068

36. Teasdale T, Christensen AL, Willems K, Deloche G, Braga L. 1997. Subjective experience in Brain Injury patients and their close relatives: A European Brain Injury Questionnaire Study. Brain Injury 8:543-563

37. Teasdale TW, Engberg AW. 2005. Subjective well-being and quality of life following traumatic brain injury in adults: A long-term population-based follow-up. Brain Injury 19:1041-1048 
38. Townsend E, Tinson D, Kwan J, Sharpe M. 2010. 'Feeling sad and useless': an investigation into personal acceptance of disability and its association with depression following stroke. Clinical Rehabilitation 24:555-564

39. Turner-Stokes L. 2008. Evidence for the effectiveness of multi-disciplinary rehabilitation

40. Van Bost G, Teasdale T, Crombez G, Cornelis A, Lorent G, Palm J, Van Weyenberg J.

41. Van Damme S, Crombez G, Eccleston C. 2008. Coping with pain: A motivational perspective. Pain 139:1-4

42. Van Damme S, Crombez G, Van Houdenhove B, Mariman A, Michielsen W. 2006. Well-

43. Viane I, Crombez G, Eccleston C, Devulder J, Decorte W. 2004. Acceptance of the unpleasant reality of chronic pain: effects upon attention to pain and engagement with daily activities. Pain 112:282-288

44. Vowles KE, McCracken LM. 2008. Acceptance and values-based action in chronic pain: A study of treatment effectiveness and process. Journal of Consulting and Clinical Psychology 76:397-407

45. Ware JE, Gandek B. 1998. Overview of the SF-36 Health Survey and the International Quality of Life Assessment (IQOLA) Project. Journal of Clinical Epidemiology 11:903912 
451 46. Whiting DL, Simpson GK, McLeod HJ, Deane FP, Ciarrochi J. 2012. Acceptance and

452 Commitment Therapy (ACT) for Psychological Adjustment after Traumatic Brain Injury:

453 Reporting the Protocol for a Randomised Control Trial. Brain Impairment 36:360-376

454 47. Wolters-Grégorio G, Ponds R, Smeets S, Jonker FA, Pouwels C, Verhey F, Van Heugten

455 C. 2015. Associations between executive functioning, coping, and psychosocial

456 functioning after acquired brain injury. British Journal of Clinical Psychology,

457 48. Wolters-Grégorio G, Stapert S, Brands I., van Heugten C. 2010. Coping styles in relation

458 to cognitive rehabilitation and quality of life after brain injury. Neuropsychological

459 Rehabilitation 20:587-600

460 49. Wrosch C, Scheier MF, Miller GE, Schulz R, Carver CS. 2003. Adaptive self-regulation

461 of unattainable goals: goal disengagement, goal reengagement, and subjective well-being.

462 Personality and Social Psychology Bulletin 29:1494-1508 
Table 1 Correlations between indicators of HRQOL, Acceptance, Life-Values-Match, illness characteristics and demographics

\begin{tabular}{|c|c|c|c|c|c|c|c|c|c|c|c|c|c|c|}
\hline Scale & Mean (SD) & Cronbach's $\alpha$ & 1 & 2 & 3 & 4 & 5 & 6 & 7 & 8 & 9 & 10 & 11 & 12 \\
\hline 1. SF-36 Physical & $41.8(9.9)$ & .89 & - & - & - & - & - & - & - & - & - & - & - & - \\
\hline 2. SF-36 Mental & $61.8(12.1)$ & .81 & $.44 * *$ & - & - & - & - & - & - & - & - & - & - & - \\
\hline 3. EBIQ Core & $55.1(12.8)$ & .92 & $-.35^{*}$ & $-66 * * *$ & - & - & - & - & - & - & - & - & - & - \\
\hline 4. Acceptance (ICC) & $14.7(4.7)$ & .85 & $.25^{*}$ & $.43 * * *$ & $-.47 * * *$ & - & - & - & - & - & - & - & - & - \\
\hline 5. Life-values-match & $4.4(1.7)$ & - & $.31^{*}$ & $.47 * * *$ & $.41^{* * *}$ & $.52 * * *$ & - & - & - & - & - & - & - & - \\
\hline 6. Self-awareness & $5.6(1.6)$ & - & $-.36^{* *}$ & -.07 & .01 & $.31^{*}$ & .22 & - & - & - & - & - & - & - \\
\hline 7. Motor problems & $3.8(1.7)$ & - & $-.58 * * *$ & -.03 & -.04 & -.19 & -.17 & .25 & - & - & - & - & - & - \\
\hline 8. Cognitive problems & $3.4(1.3)$ & - & .11 & -.08 & .18 & -.15 & -.15 & $-.32 * *$ & -.09 & - & - & - & - & - \\
\hline 9. Communication problems & $2.7(1.8)$ & - & $-.25^{*}$ & -.06 & .10 & $-.24 *$ & -.10 & .05 & $.42 * * *$ & -.07 & - & - & - & - \\
\hline 10. Gender (male) & - & - & $.27^{*}$ & .11 & -.06 & $.25^{*}$ & .02 & .04 & -.01 & -.02 & -.21 & - & - & - \\
\hline 12. Education (years) & $12.4(2.9)$ & - & .03 & .16 & -.04 & -.01 & -.09 & -.03 & .13 & .08 & -.09 & .18 & -.06 & - \\
\hline 13. Time since injury (months) & $25.6(27.8)$ & - & .14 & -.02 & .19 & -.02 & .04 & -.18 & -.23 & -.15 & -.12 & -.01 & $-.25^{*}$ & -.19 \\
\hline
\end{tabular}


Table 2: Hierarchical regression analyses on different indicators of HRQOL (final model)

\begin{tabular}{|c|c|c|c|c|c|}
\hline Dependent variable & Step & Predictors & $\beta$ (standardized) & $\Delta \mathrm{R}^{2}$ & $\mathrm{R}^{2}$ (adjusted) \\
\hline \multirow[t]{9}{*}{ SF 36 Physical } & 1 & Gender & $.21 *$ & $.15^{*}$ & .11 \\
\hline & & Age & -.18 & & \\
\hline & & Education & .11 & & \\
\hline & 2 & Time since injury & -.03 & .01 & .10 \\
\hline & 3 & Self-awareness & $-.24 *$ & $.34 * * *$ & .43 \\
\hline & & Motor problems & $-.54 * * *$ & & \\
\hline & & Cognitive problems & -.04 & & \\
\hline & & Communication problems & .10 & & \\
\hline & 4 & Acceptance & .20 & .03 & .45 \\
\hline \multirow[t]{9}{*}{ SF 36 Mental } & 1 & Gender & -.01 & .04 & -.01 \\
\hline & & Age & -.04 & & \\
\hline & & Education & .17 & & \\
\hline & 2 & Time since injury & .04 & .00 & -.02 \\
\hline & 3 & Self-awareness & -.26 & .02 & -.07 \\
\hline & & Motor problems & .07 & & \\
\hline & & Cognitive problems & -11 & & \\
\hline & & Communication problems & .08 & & \\
\hline & 4 & Acceptance & $.53 * * *$ & $.22 * * *$ & .16 \\
\hline \multirow[t]{9}{*}{ EBIQ Core } & 1 & Gender & .07 & .01 & -.04 \\
\hline & & Age & -.04 & & \\
\hline & & Education & .03 & & \\
\hline & 2 & Time since injury & .18 & .04 & -.02 \\
\hline & 3 & Self-awareness & $.33^{*}$ & .04 & -.03 \\
\hline & & Motor problems & -.20 & & \\
\hline & & Cognitive problems & .15 & & \\
\hline & & Communication problems & .07 & & \\
\hline & 4 & Acceptance & $-.57 * * *$ & $.25 * * *$ & .23 \\
\hline
\end{tabular}

${ }^{*} P<.05 .{ }^{* *} P<.01 .{ }^{* * *} P<.001$. 
Figure 1: Mediation of Life-Values-Match between Acceptance and QOL

Mediation of Life-Values-Match between Acceptance and Mental HRQOL (SF-36)

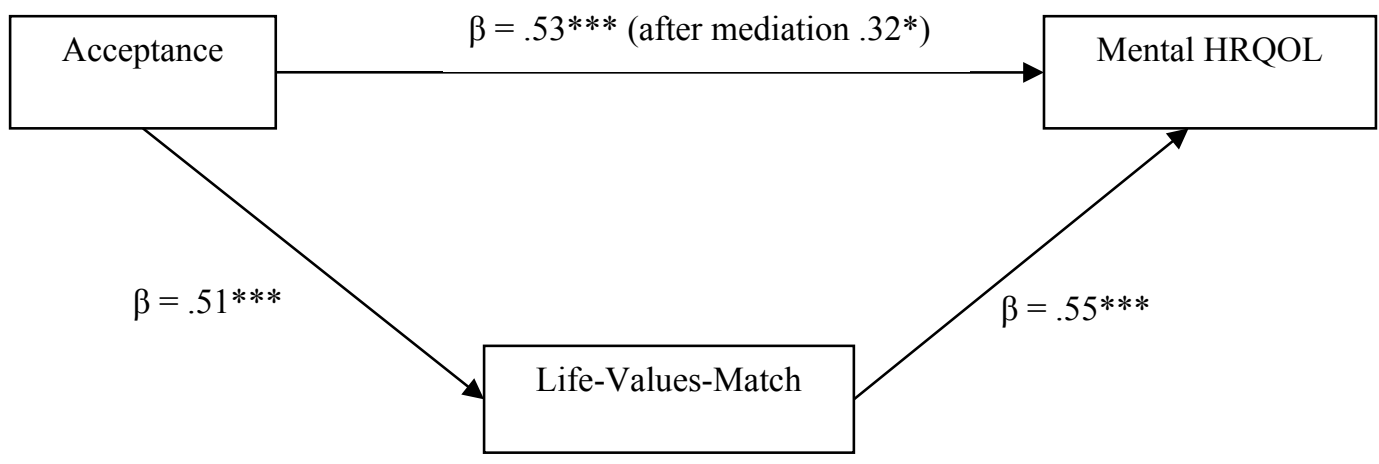

Sobel Test Statistic: $3.11 ; \mathrm{p}<.01$

Mediation of Life-Values-Match between Acceptance and Disease specific QOL (EBIQ)

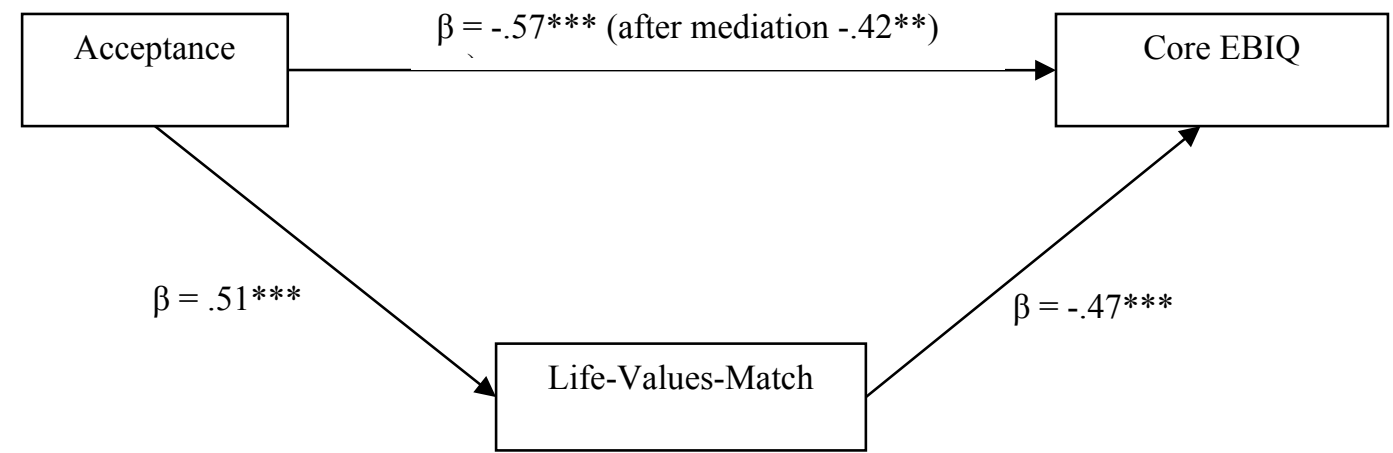

Sobel Test Statistic: $-2.83 ; \mathrm{p}<.01$ 